\title{
The Protection and Inheritance Research of Qiang People Folk House Architectural Vulture
}

\author{
Xiayan Liao, Jinxiu Wang
}

School of Fine Arts, Leshan Normal University, Leshan, Sichuan Province, China

Keywords: Qiang people folk houses, Architectural culture, Architectural culture protection, Architectural culture heritage.

\begin{abstract}
Qiang people are an ancient Chinese nation, mostly concentrated in the eastern edge of Qinghai-Tibet plateau alpine or mid-levels area. Qiang village built around the mountain, according to the risk, its representative is its towers -- the room. A dozen or dozens of gather together are into a village. Qiang building towers, stone house built dam, bridge, road and water conservancy etc. This article discusses Qiang local-style dwelling houses building culture protection and inheritance.
\end{abstract}

\section{Introduction}

Qiang is one of the ancient and excellent people in the big family of nationalities in China. As early as three thousand years ago are shells of oracle, regarding the "Qiang" clear records. Many history books and unearthed relics show that Qiang not only is an important part of Chinese family, and is among the first to enter farming concurrently, and well known for its sheep and ethnic groups. Shigeru are mainly distributed in the Alba Tibetan autonomous prefecture, Sichuan province (Qiang autonomous county territory, some live in Wenchuan, Wenzhou, Heishui county, the finest, etc [1]. A population of about one hundred and ninety-eight thousand people (1990), most concentrated in mountain or mid-levels area, a few distributions near the cities along the road, and of a number of Tibetan, Han, Hui and other peoples.

The Qiang language belongs to Sino-Tibetan language. Points in the two dialects, southern dialects are including autonomous county of the south in northern, central and south region; Northern dialects including autonomous county in northwest of red not Sue, etc. Due to long-term relationship with the Han people's frequent, a lot of the Qiang people understand Chinese provinces. Located in the alpine valleys between Qiang areas, the climate is mild, moderate rainfall [1]. Because of the different terrain, climate difference is extremely obvious. River, in the $1300 \mathrm{~m}$ to $1400 \mathrm{~m}$ above sea level, early spring season, the flowers in bloom, and elevation in more than two kilometers of the mountains, but is still snowy cold weather.

\section{The cultural characteristics of Qiang local-style dwelling houses building}

Diaolou built near the village of housing, $10 \mathrm{~m}$ to $30 \mathrm{~m}$ high, to against the enemy and stored grain straw. Are the four corners in several forms, hexagonal and octagonal (such as Fig. 1). Building material is flake and yellow soil. Stone walls inside vertical to the ground, lateral by and slightly tilted upward. Building strong, enduring [1]. In Sichuan's Beichuan county township Qiang Yong An Village 1988 discovered a site of the Ming dynasty ancient castle "fort" Yongping, after hundreds of years of wind and rain vicissitudes of life are still intact.

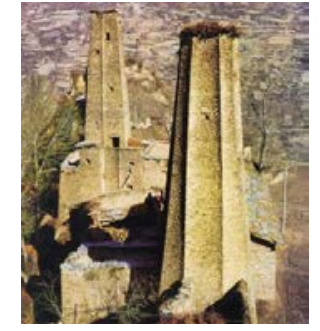

Fig. 1 Qiang diaolou local-style dwelling houses 


\subsection{Living residential towers room.}

QiangZhai generally located in the mountains or Taiwan area the ground, a complete platform often according to by a bandit; a few are distributed in the river valley. Living residential towers room shows square, compare diminutive, flake bricks, ceiling, generally three layers, each layer is about 3 meters [2]. The underlying captive animals, heap for toilets. Is generally a room and the bedroom on the second floor, some stockade will pen built beside the subject construction, set up a separate entrances and exits, the underlying set the main central, the moderate position of build by laying bricks or stones a short, square the fire burning wood all the year round and round [2]. Dwarf neutral one called kettle triangular metal frame, head of 1 meter in diameter, is cooking pot, the fire blocking effect, and as a family heirloom for generations. Or is a shrine in the class, for sacrifices to ancestors, god, the god of wealth, and so on. Family gathered at ordinary times, food, song and dance festival, greeting guests and ancestor worship, around the fire hall.

\subsection{Defense bleaching room.}

Such residential towers room distribution on or near the village settlement center, generally there are six or seven layers, each layer of shot hole and can live at ordinary times, inventory, livestock, soldiers do resist the intrusion barrier. Garrison climb the lookout, once found enemy with predetermined signal to all villages, certify the beacon tower and watcher. If the foreign invasion, young and old women and children can be inside, QingZhuang man but also with the advantages of commanding, kill the enemy [3]. Each village has a few commonly.

\subsection{The war bleaching room.}

Such residential towers room dedicated to fighting, bleaching height is big, and generally there is six or seven layer, according to the village far away. Towering in north-west risks, and observation and the role is passing information. The Qiang people mostly live in mountains or mid-levels area, every village three, five to ten, but three, 50 households for a village in the majority [3]. Qiang folk house is built of stone chips PingDingFang, square, mostly 3 layers; each layer is more than $3 \mathrm{~m}$. At the bottom of the roof platform is wood or SLATE, out of the wall into the roof. Wood or SLATE densely covered on limb or bamboo, gland compaction loess and chicken manure, about 035 meters thick, with holes in water, does not leak rain and snow, warm in winter and cool in summer.

\subsection{Building techniques.}

Flat peach QiangZhai is a typical representative of the Qiang village. Peach QiangZhai aba prefecture on the river is located in the upper Minjiang River miscellaneous ancient brain Gutang Peach Township 163 kilometers from Chengdu, 41 kilometers distance from the county seat, has been 2000 years of history, is the only well-preserved QiangZhai China [3]. Still preserve the original QiangZhai architectural culture art "living fossil", was praised as "mysterious castle of the Orient". QiangZhai buildings during construction drawing, building, mud and stone, but after one thousand years of wind and snow have stood up to magnitude 8 earthquake, and thousands of aftershocks, peach QiangZhai still standing. Without the overall collapse earthquake in a house in good condition, shows as Fig. 2.

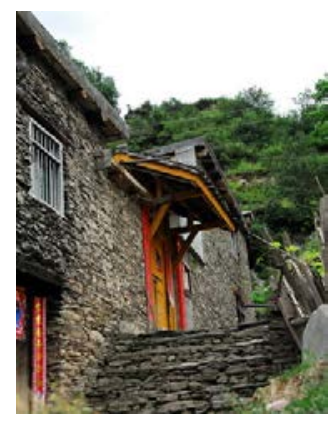

Fig. 2 Qiang village building techniques

Peach QiangZhai was built in 111 BC, more than two thousand years of history, it is a typical 
representative of the Qiang architecture, it intact ancient Qiang ethnic characteristics, surface water back mountain, sits, layout strict neatly. Buildings are all assembled in stone and become, from a distance, a piece of brown stone are along the steep mountain in accordance with the slope on the successive tired, or high or low strewn at random have send, during which the bunker, splendid, with a unique style [4]. Qiang building exquisite workmanship, unique idea, to defense the enemy invasion, all housing connected to each other, into the tunnel, it's like going to a nightmarish, ancient Qiang ancestors lead mountain spring repair drainage flows from under the village houses within, drinking and fire water is very convenient.

\section{Qiang local-style dwelling houses building "fossils"}

Qiang is commonly by a few hundreds of households or family form "QiangZhai" in a race. For farming, pastoral life convenient both security, build QiangZhai multi-select high in the mountain valley, a mountainside, mid-levels.

In terms of space form, have Diaolou centered space, such as the Wenchuan in Sichuan province Qiang feng village, village, Maoxian county black tiger village; Have centered on channels of space, such as wenchuan stream village, Guo Zhu shop village, a large peach village, Tonghua village, wooden card village; Has centered on road and bridge gallery space, such as a large old wood village, peach village, Maoxian county Knapp village; Have officer for the village centered space, such as Maoxian county Magaritani hexed village is that Taichung officer Wang village as the center of the space form. Constitutes the type is rich, flexible space combination and space environment of nature and man [4].

For the defensive towers in the Qiang local-style dwelling houses building occupies an important position, it is in order to adapt to the environment and the military defense facilities. Progressive loss of just towers for its defense function has declined [5]. Now remains of the towers are mainly concentrated in Maoxian, Wenchuan, Sichuan province, Wenzhou and other places, are the Ming and Qing dynasties buildings, with their residences, village form a grand and tight defenses.

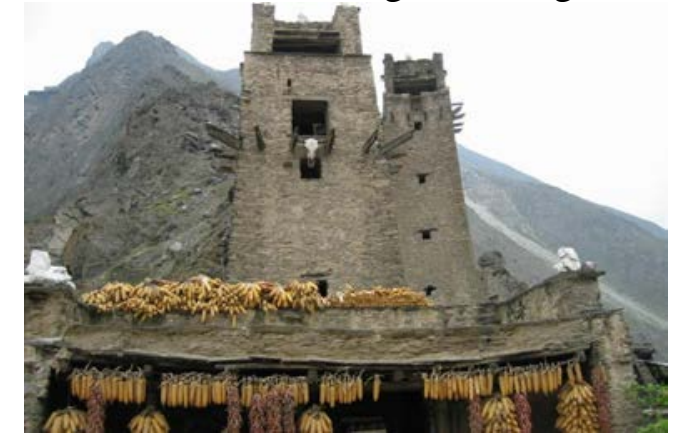

Fig. 3 Qiang folk houses

\section{The protection of the Qiang folk house}

\subsection{Do a good job in urban planning.}

In the current rapid economic development, the modernization of cities and towns in the process of urbanization, many should have been saved and the protection of ancient buildings was destroyed in the tide of modernization construction in the city. How the urban development at the same time, better has to strengthen the protection of ancient buildings has become a need to ponder earnestly and important problem to be solved. Ancient city of Italy is "give up, and the other built new city", is worth our using for reference [5]. In Lyon, France, retain 12 - still intact ancient lane area in the 16th century building, 250 to protect the building area. In 19th century, the construction of the building is the style and ancient buildings. In China, there are worthy of reference. Such as Ningbo urban greening construction in moon lake area, is to keep the period of northern song dynasty ", "the Korean embassy sites such as a few ancient buildings of great historical value and artistic value. 


\subsection{Strengthen the protection consciousness.}

Ancient architecture is an important part of cultural heritage, is non-renewable cultural resource, only the consciously join to the protection of ancient buildings can be eternal [6]. Protection is the common obligation of the whole society, the cultural relics, the nation should enhance the awareness of the protection of ancient buildings.

\subsection{Improve the technology content.}

Ancient architecture protection of each intervention and repair activities all needs to have a correct theory instruction, in the early stage of the thorough historical data and archaeological research, investigation and survey, record, analysis, and so on as the basis and premise, relevant multidisciplinary cooperation [6]. By multi-disciplinary comprehensive research, cooperate with each other, use the knowledge of the interdisciplinary study of ancient buildings, help to achieve the scientific understanding of ancient buildings. In the process of restoration of ancient buildings, compared with the traditional technology and modern science and technology can be more comprehensive, precise and deep cognitive ancient buildings, protection measures can be more targeted and more scientific [6]. As with the rapid development of computer and related technology, now the digital close shot photogrammetric, 3 d laser scanning measurement, such as virtual reality technology based on digital protection and restoration began used in ancient architecture protection, and plays an important role. Now as long as we reasonable use of science and technology, combined with the traditional technology, can be appropriate, suitable for the protection and restoration of ancient buildings.

\section{The inheritance of Qiang folk house}

\subsection{The ancient dwellings are a carrier of Qiang culture.}

Qiang has a splendid culture, is an ancient art but also the classic of Oriental art. Qiang ancient buildings is a kind of cultural carrier of the spirit, through the ancient buildings, can understand the rich cultural connotation. In a sense, they are a city symbol "historical memory" and "urban culture development of chain", because they saw the hundreds or even thousands of year's history of the city's vicissitudes of life change. Once the damage, would be difficult to restore and succeeded. Records of history, culture, carrying the soul, is the real meaning and value of ancient buildings [7]. Will of the historical factors of the ancient building complete inheritance and expression, is the real meaning of ancient architecture protection today. So, we go to admire the ancient architecture should not only focus on its external aesthetic characteristics, more should be through the ancient buildings of brick wall see its inherent cultural charm.

\subsection{Ancient architecture is an important part in the artistic creation.}

China's ancient architecture in art and technology have reached a very high level, on the world history of architecture is very rich and brilliant achievements. China's ancient architecture in the layout, material, construction, decoration, etc. , is for thousands of years of countless artisans in long-term accumulated more experience in architectural practice [7]. These ancient technological achievements, the existing relevant professional personnel, have great enlightenment and exemplary role. As China's ancient timberwork building principle and its unique shock method, for the development of modern structural seismic technology is of great significance.

\subsection{Ancient building is the important material base of tourism.}

With the development of production, material life level continuously improves, people's need for culture will be more urgent. Ancient buildings in the new period take on the new historic mission of cultural leisure places. If a tourist destination with unique ancient buildings, the ancient buildings will play a very important role. Ancient architecture resource itself has the enormous brand effect, can improve the tourists visit rate over a long distance [7]. These places of historic interest in attracting more and more domestic and foreign friends come to tour, to promote the development of urban 
tourism and the local economy and created good conditions. At the same time, also that led to the rapid development of urban transportation and services and other related industries.

\section{Summary}

Qiang folk houses is the memory of a nation, national culture witnesses of history, it is bearing the weight of the culture of a nation. Once the damage, the history of cultural relics of ontology and its bearing cultural information will cease to exist. All in all, only the dwellings protection, repair good, let them permanently preserved in its original look, to play a "physical history", "annals of history", "and the carrier of culture" and so on. Protection of ancient dwellings is each one of us should bear social responsibility.

\section{References}

[1] T. Y. Liu, Historical and cultural city and ancient architecture protection corpus, Beijing: China building industry press, 2011, vol. 2, pp. 19-22.

[2] P. P. Bao, The proceedings of the inheritance and protection of cultural heritage architecture, Tianjin: Tianjin university press, 2012, vol. 4, pp. 11-13.

[3] B. B. Cheng, The significance and measures of protection of ancient buildings, Anhui construction, 2011, vol. 2, pp. 18-25.

[4] Sh. T. Li, Ancient architecture protection method of digital research, Journal of Wuhan university (Engineering science), 2012, vol. 2, pp. 12-14.

[5] X. J. Li, Chinese architectural heritage protection countermeasures, New buildings, 2003, vol. 4, pp. 26-28.

[6] J. F. Pan, The theory of traditional Chinese filial piety culture and its history, journal of boat hill, 2005, vol. 3, pp. 22-25.

[7] L. S. Qi, Theory of Qiang traditional ethics thought, The Chinese market, 2010, vol. 9, pp. 56-60. 